\title{
Fitoplancton del Golfo de Cariaco, estado Sucre, Venezuela
}

\author{
Amelia La Barbera - Sánchez ${ }^{1}$, Jesús F. Gamboa - Márquez ${ }^{1}$ y William Senior² \\ 1 Centro de Investigaciones Agropecuarias del Estado Sucre - FONAIAP. Av. Carúpano, sector Caigüire. Cumaná, \\ Estado Sucre. Venezuela. Apartado Postal No 236. Fax. 58(93)317557. e-mail: ciapes@ sucre.udo.edu.ve \\ 2 Instituto Oceanográfico de Venezuela, Universidad de Orientc. Cumaná, Estado Sucre. Venezuela.
}

Recibido 14-1-1999. Corregido 12-III-1999. Aceptado 12-IV-1999.

\begin{abstract}
Phytoplankton was sampled monthly during the June 1995-May 1996 period, at 16 stations of the eastern Gulf of Cariaco. This area receives different wastes. Only chlorophyll and diatoms, dinoflagellates, and total density of phytoplankton varied by depth. Only salinity and oxygen showed horizontal spatial differentiation. Phytoplankton maxima in November- December, were related with low nitrogenous nutrients and temperature, high phosphate, chlorophyll, and dissolved oxygen. The June-October period was characterized by high temperature, low oxygen, nutrient concentrations and phytoplankton abundance. Overall, phytoplankton abundances were low. Diatoms dominated during the sampling period, but microflagellates and dinoflagellates did occasionally. Phytoplankton density was positively correlated with phosphate and negatively with nitrogen. In spite of the high nutrient supply, phytoplankton growth was limited by a reduced light penetration related to concentrations of suspended particles.
\end{abstract}

Key words: Phytoplankton, nutrients, ecology, Gulf of Cariaco, Venezuela.

El Golfo de Cariaco, en la costa oriental de Venezuela, es un sistema semicerrado de $616 \mathrm{~km}^{2}$ que recibe descargas de diversos tipos en su porción oriental. Durante los primeros meses del año, esta área es afectada por la surgencia que incrementa los nutrientes y en el período de su máxima intensidad se presentan las mayores concentraciones de fitoplancton (Gade 1961, Richards 1960, Simpson y Griffiths 1971). La composición y abundancia del fitoplancton en el Golfo, ha sido estudiada por Ferraz-Reyes (1976, 1987), en función de las épocas de surgencia y de no surgencia. FerrazReyes y Fernández (1990) estudiaron el ciclo anual de bacterias heterótrofas y el fitoplancton, encontrando relación entre el fitoplancton y el bacterioplancton al dominar diatomeas y dinoflagelados.

Existe poca información sobre la dinámica del fitoplancton en la región oriental del Golfo de Cariaco; en este trabajo se estudia el comportamiento del fitoplancton en una zona que recibe descargas de tipo industrial, domésticas y naturales.

\section{MATERIALES Y MÉTODOS}

Se muestrearon mensualmente 16 estaciones en el Golfo de Cariaco (Sector Oriental), de junio 95 a mayo 96 (Fig.1). Se tomaron muestras de superficie y fondo, se fijaron con lugol y se estimó la abundancia de fitoplancton (Utermöhl 1958). Euglenofitas, microflagelados y crisofitas no fueron identificados pero sí contados e incluidos en el grupo microflagelados. Cocolitofóridos y silicoflagelados se incluyeron en el grupo denominado "otros". Para estudios cualitativos, se realizaron muestreos verticales con red de plancton (malla de $25 \mu \mathrm{m}$ ). Las muestras se colocaron en botellas de $125 \mathrm{ml}$ y se preservaron con formalina neutralizada al $4 \%$. Se midió temperatura, salinidad por conductividad y se tomaron muestras para análisis de clorofila $a$, oxígeno disuelto 
(método de Winkler) y nutrientes (nitratos, nitritos, amonio y fosfato) (Strickland y Parsons 1972). Para los análisis estadísticos los datos de abundancias del fitoplancton se transformaron a logaritmo $\left[\log \left(x+1.10^{-6}\right)\right]$ para normalizar los datos. Se estudió el efecto diferencial de la profundidad y la localidad de muestreo sobre las variables biológicas, físicas y químicas mediante un análisis de varianza de una vía y prueba a posteriori SNK.

\section{RESULTADOS}

La primera s̀erie de análisis de varianza se efectuó sobre los datos de la profundidad de
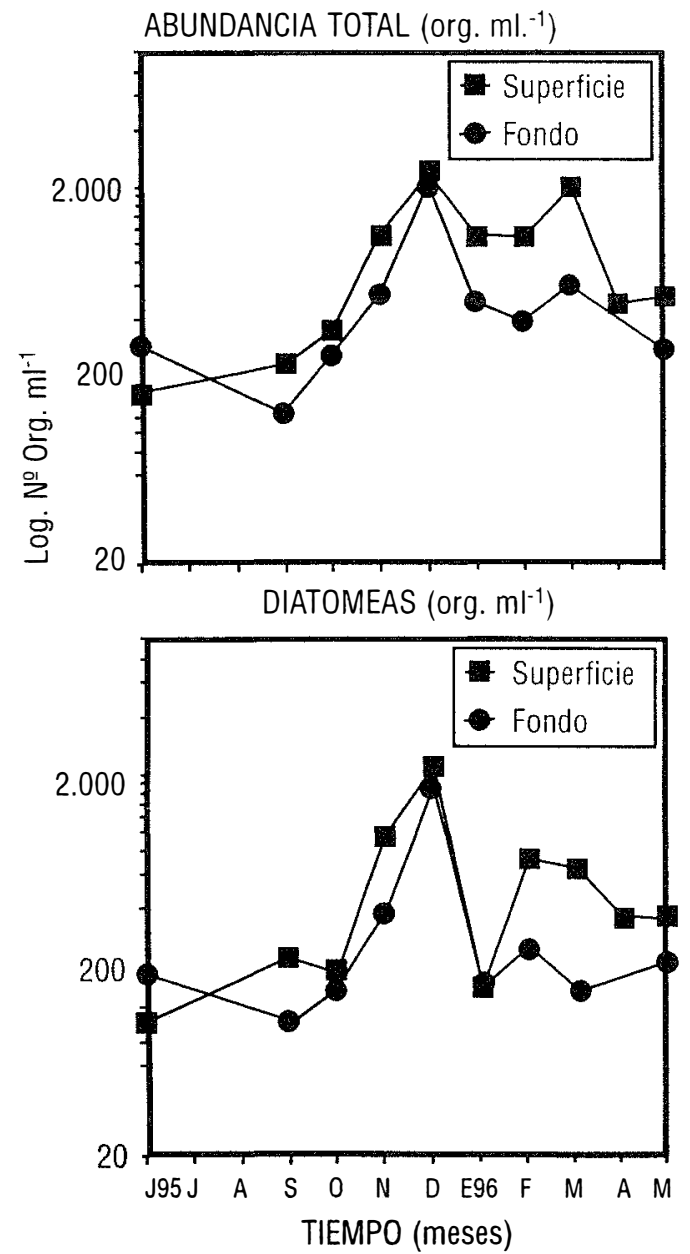

muestreo (superficie y fondo). Los datos mostraron ser homogéneos; normales e independientes. El análisis de varianza mostró una diferencia altamente significativa ( $<<0.001$ ) entre superficie y fondo para las abundancias de diatomeas, dinoflagelados y los totales. Las muestras de fondo presentaron el promedio de abundancia mas bajo. No hubo diferencias significativas con cambio de localidad.

En ambas profundidades la abundancia del fitoplancton fue inferior a 2500 org. $\mathrm{ml}^{-1}$ con dos pulsos: uno de noviembre 95 a enero 96 (de 2300 a 1174 org. $\mathrm{ml}^{-1}$ en superficie y de 1900 a 1052 org. $\mathrm{ml}^{-1}$ en fondo) y el otro menos conspicuo de febrero a marzo (Fig. 1). La
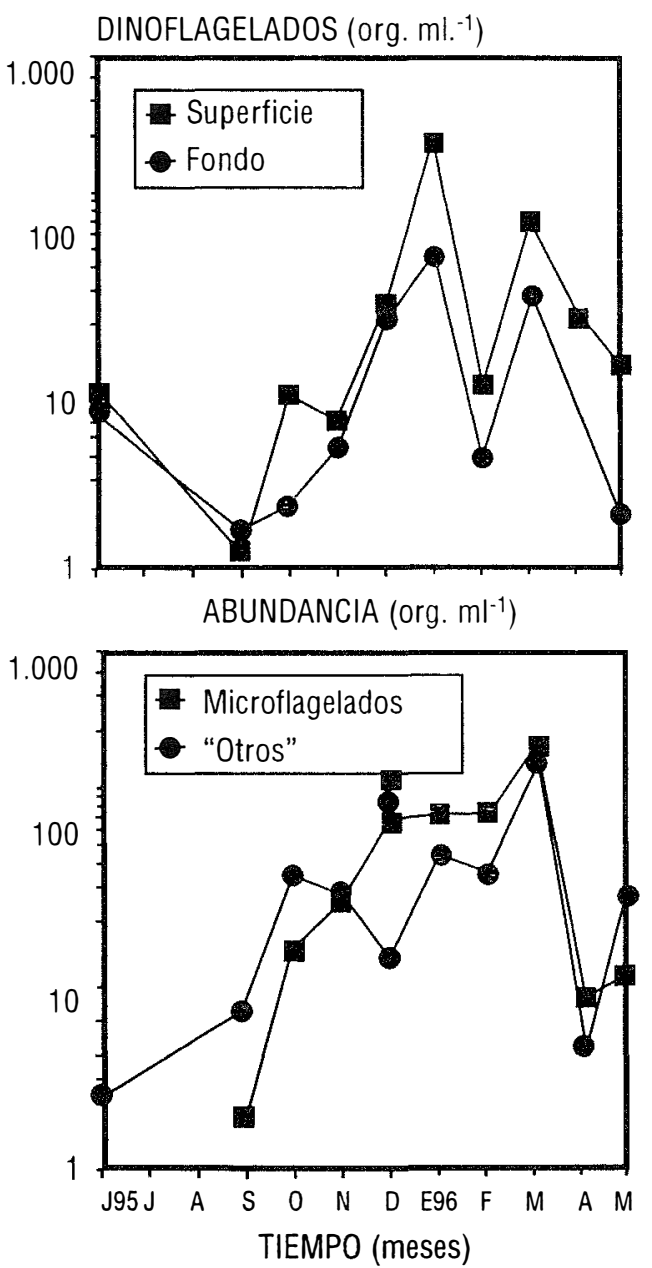

Fig. 1. Variación mensual promedio de la abundancia total del fitoplancton diatomeas, dinoflagelados, microflagelados y "otros". 
Clorofila a $\left(\mu \mathrm{g}^{-1}\right)$

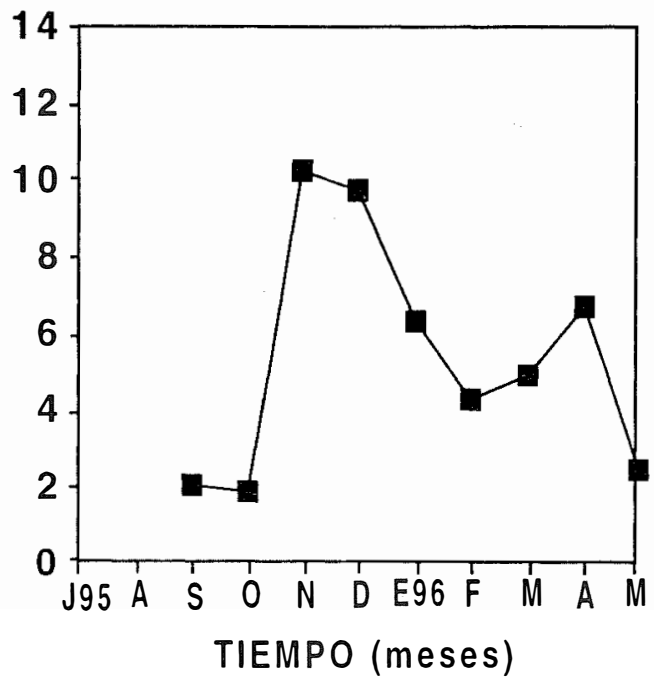

Clorofila a $\left(\mu \mathrm{g} \mathrm{I}^{-1}\right)$

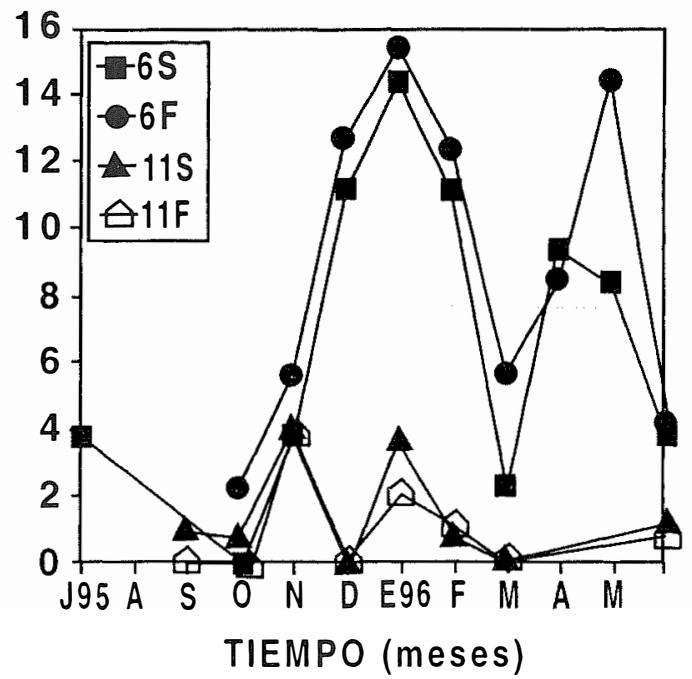

Fig. 2. Variación mensual promedio de la clorofila a y variación en superficie y fondo de las estaciones 6 y 11 .

abundancia máxima se encontró en diciembre 95 (2 379 org. $\mathrm{ml}^{-1}$ en superficie y 1933 org. $\mathrm{ml}^{-1}$ en fondo) y estuvo favorecida por diatomeas, particularmente las formadoras de cadenas y de estructuras alargadas como Leptocylindrus danicus, Nitzschia seriata y Skeletonema costatum, también contribuyeron los dinoflagelados, microflagelados y otros (Fig. 1). Los grupos fitoplanctónicos mantuvicron la misma tendencia. En enero se notó un marcado descenso en diatomeas y dinoflagelados, no observado en los otros grupos, que incrementaron su número entre febrero y marzo.

La varianza de la clorofila mostró diferencias muy significativas $(p<0.01)$ entre superficie y fondo. La variación mensual promedio en ambas profundidades, fluctuó similar a la abundancia del fitoplancton (Fig. 2). Las mayores concentraciones del pigmento se encontraron en noviembre, diciembre, enero ( $>10$ $\left.\mu \mathrm{g} . \mathrm{l}^{-1}\right)$ y abril $\left(7 \mu \mathrm{g} . \mathrm{I}^{-1}\right)$.

La clorofila $a$ presentó diferencias altamente significativas ( $\mathrm{p}<0.001)$ entre estaciones. La 2, 6 y 7 (sector oriental) alcanzaron valores superiores a $4 \mu \mathrm{g}$. at. $\mathrm{l}^{-1}$ y la 11 y 13 (sector occidental) inferiores a $4 \mu \mathrm{g}$. at. $1^{-1}$, las restantes presentaron valores similares a las estaciones 11 y 13. Para observar la variación de la clorofila en cada sector, se tomaron las estaciones 6 y 11 como representativas. En la 6 la clorofila a mostró dos máximos en superficie y fondo, uno en enero y otro en abril (>13 $\left.\mu \mathrm{g} . \mathrm{l}^{-1}\right)$. En la 11 los máximos se registraron en noviembre y enero en superficie ( $3.7 \mu \mathrm{g} . \mathrm{l}^{-1}$ y 3.6 $\mu \mathrm{g} . \mathrm{l}^{-1}$ respectivamente) (Fig. 3 ).

El análisis de varianza para la temperatura no mostró diferencia significativa con la profundidad ni con las estaciones. La variación promedio exhibe un período de altas temperaturas de septiembre a octubre con un valor máximo $\left(29,5^{\circ} \mathrm{C}\right)$ en septiembre, seguido de temperaturas frías con un mínimo de $23{ }^{\circ} \mathrm{C}$ en marzo, en abril aumenta nuevamente (Fig. 3). Este patrón de temperatura es típico en la zona, comportamiento que marca la estacionalidad del área.

La salinidad no mostró diferencias significativas con la profundidad, pero hubo diferencias altamente significativas $(p<0.001)$ entre las estaciones: 1 salinidad baja, 2 intermedia y las restantes altas. La salinidad fluctuó marcadamente en las estaciones 1 y 2, estabilizándose a partir de enero. En noviembre, la estación 1 presentó la salinidad mas baja $(14,78 \%$ y una relación negativa con la estación 2 , que aumentó su contenido salino (37). Las restantes 
TEMPERATURA $\left({ }^{\circ} \mathrm{C}\right)$
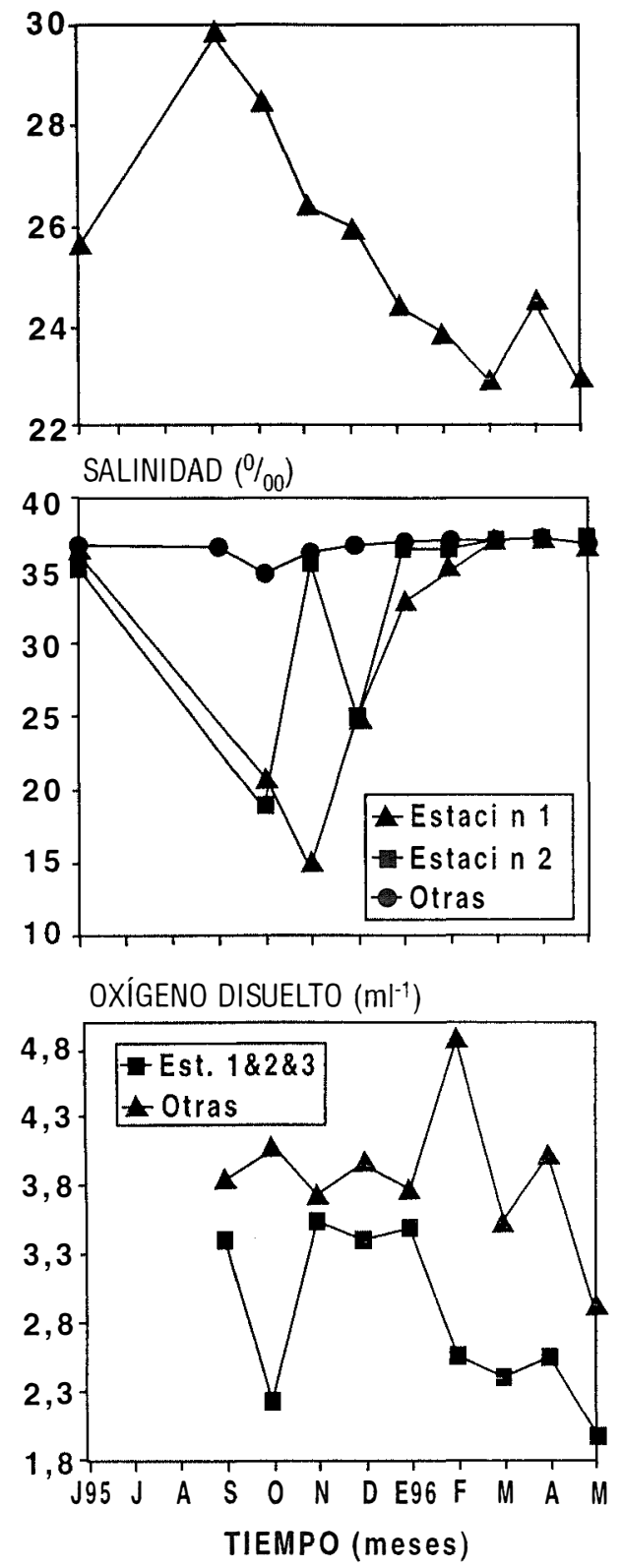

Fig. 3. Variación mensual promedio de la temperatura, salinidad y oxígeno.

estaciones (grupo otros), variaron poco (de 36 a 37) (Fig. 3). Las estaciones 1 y 2 se encuentran ubicadas en el extremo más oriental del Golfo de Cariaco y reciben directamente la influencia de los aportes del Río Carinicuao.
Los análisis de varianza para el oxígeno, no mostraron diferencias significativas para la profundidad pero fueron altamente significativos $(p<0.001)$ para las estaciones y separa a la 1,2 y 3 con los niveles más bajos y a la 6,10 , 11 y 14 con los mas altos. Las estaciones 1,2

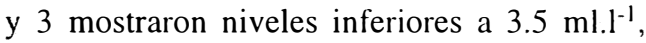
con mínimos en octubre ( $\left.2.2 \mathrm{ml}^{\mathrm{I}^{-1}}\right)$ y de febrero a mayo 96 ( menor a $2.5 \mathrm{ml}^{. \mathrm{l}^{-1}}$ ) (Fig. 3). Las restantes estaciones presentaron valores superiores a $3.8 \mathrm{ml} . \mathrm{I}^{-1}$ y un máximo en febrero de $4.9 \mathrm{ml}^{-\mathrm{I}^{-1}}$.

El nitrato, nitrito y amonio no mostraron diferencias significativas con la profundidad ni con las estaciones. El nitrato y el nitrito mantienen tendencia similar, valores bajos de junio 95 a enero 96 (nitrato $<3 \mu \mathrm{M} . \mathrm{l}^{-1}$ y nitrito $<1$

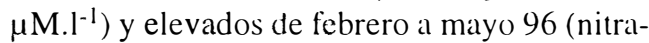
to $>4 \mu \mathrm{M} . \mathrm{I}^{-1}$ y nitrito $>1 \mu \mathrm{M} . \mathrm{I}^{-1}$ ). El amonio fluctuó diferente, aumentos de agosto a octubre y de febrero a mayo (niveles hasta de 3.5 $\left.\mu \mathrm{M} . \mathrm{l}^{-1}\right)$ y descensos de noviembre a enero $(<$ $0,5 \mu \mathrm{M} . \mathrm{I}^{-1}$ ) (Fig. 4). El fosfato fluctuó igual que el nitrato y nitrito, excepto los incrementos de noviembre y diciembre. Las concentraciones se mantuvieron menores a $1 \mu \mathrm{M} . \mathrm{l}^{-1}$, de junio a marzo y aumentaron hasta $2.2 \mu \mathrm{M} .1^{-1} \mathrm{en}$ mayo (Fig. 4).

\section{DISC.USIÓN}

En trabajos previos se ha determinado que las frecuentes fluctuaciones en el patrón de los vientos causan cambios en la intensidad de la surgencia y en la distribución estacional de la biomasa fitoplanctónica (Ferraz-Reyes 1987; Mandelli y Ferraz-Reyes 1982, Okuda 1981). Nuestros resultados indican una clara diferenciación temporal de las muestras a principio, mediados y final del muestreo. Esta separación depende en su mayor parte de los parámetros ambientales, la concentración de clorofila y la abundancia del fitoplancton.

De junio a octubre la temperatura se distri'buyó homogéneamente horizontal y verticalmente, indicativo de la existencia de mezcla en la columna de agua. Las aguas cálidas de septiembre-octubre $\left(26-30{ }^{\circ} \mathrm{C}\right)$ fueron sustituidas 
NITRÓGENO $\left(\mu \mathrm{M} \mathrm{I}^{-1}\right)$

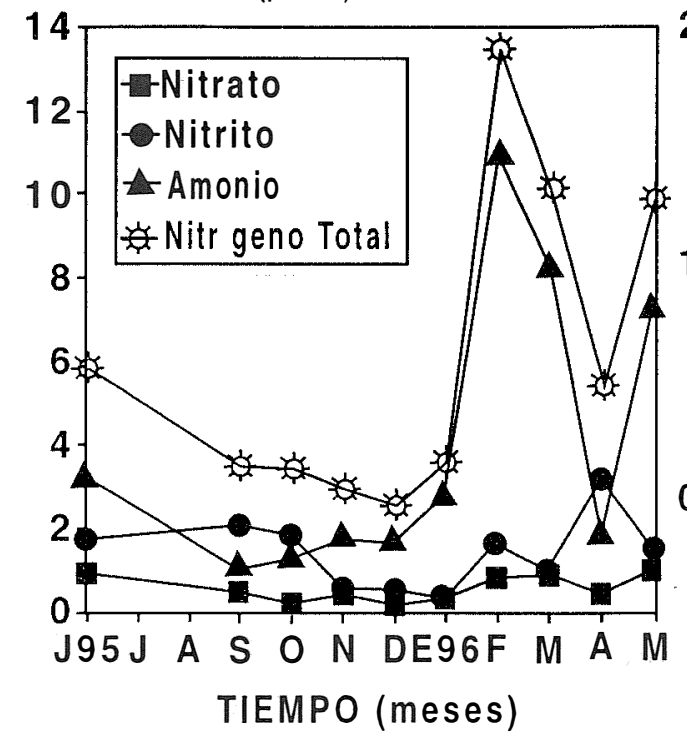

FOSFATO $\left(\mu \mathrm{M} \mathrm{I}^{-1}\right)$

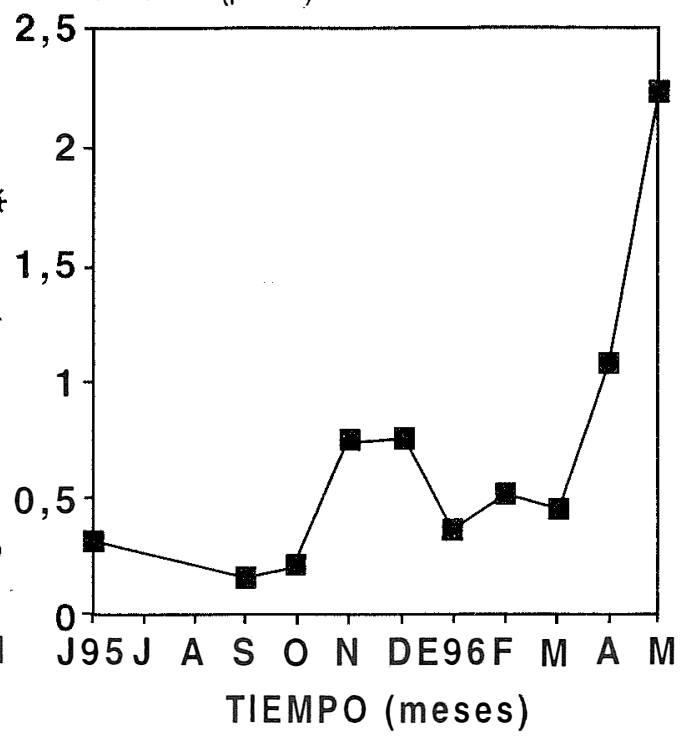

Fig. 4. Variación mensual promedio del nitrógeno en sus diversas formas y del fosfato.

por aguas frías, de elevada salinidad en las zonas central y occidental y de baja salinidad en la oriental (estaciones 1 y 2). Esto se asecia con la intrusión de agua dulce proveniente del Río Carinicuao. La separación de las estaciones 1, 2 y 3 del resto, por su bajo contenido de oxígeno disuelto $\left(<3.5 \mathrm{ml} . \mathrm{1}^{-1}\right)$, posiblemente se origina en los precesos de descomposición de la materia orgánica que es arrastrada por el río. Los efluentes aumentaron el material en suspensión, lo que afectaría la penetración de luz y junto a los otros factores contribuir al declive observado en la abundancia del fitoplancton ( menores a 200 org. $\mathrm{ml}^{-1}$ ) y en la concentración de clorofila $\left(<2 \mu \mathrm{g} \cdot \mathrm{l}^{-1}\right)$. Las diatomeas dominaron y descendió la abundancia de los dinoflagelados. Observaciones similares de dominancia fueron realizadas en el Golfo de Cariaco por Ferraz-Reyes (1987). Durante estos meșes la surgencia se debilita y se observan

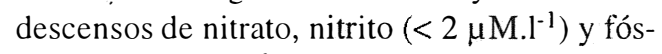

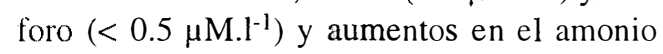
(niveles aproximados a $2 \mu \mathrm{M} .1^{-1}$ ), posiblemente por los aportes del río y a la actividad acuícola desarrollada en la zona (ver Goldman et al. 1979).
En noviembre y diciembre los descensos de la temperatura coinciden con aumentos en el oxígeno, máximos de fitoplancton (1 500$\left.2000 \mathrm{org} . \mathrm{ml}^{-1}\right)$ a nivel superficial y de clorofila $\left(>9 \mu \mathrm{g} \cdot \mathrm{l}^{-1}\right)$. Estas características son propias del proceso de mezcla típico del período de la surgencia. En diciembre, la salinidad aumentó en las estaciones 1 y 2 , por el descenso en el caudal del río Carinicuao debido al cese del período de lluvias, las restantes estaciones se mantuvieron en $36 \%$. Particularmente en noviembre se nota un comportamiento inverso entre las estaciones 1 y 2 , atribuida a las descargas de la empresa camaronera.

La alta concentración de clorofila en este período, se relaciona con aumentos de fosfato

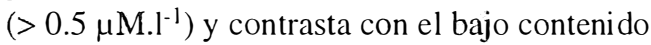

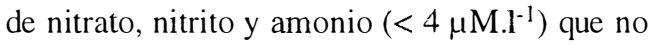
limitaron el crecimiento del fitoplancton. En este período el rápido crecimiento del fitoplancton favoreció el florecimiento de diatomeas (Leptocylindrus danicus, Nitzschia seriata y Skeletonema costatum), seguido de aumentos de los dinoflagelados y microflagelados y de un incremento en el número de especies, principalmente diatomeas. Al respecto, MacIsaac (1978) se- 
ñaló que una concentración de $0.2 \mu \mathrm{M} . \mathrm{l}^{-1}$ de nitrógeno permite el crecimiento y desarrollo de organismos tropicales.

En enero, febrero y marzo la intrusión de agua de mayor salinidad mantiene una concentración salina constante en toda el área (36-37), se acentúa la surgencia y llegan a la superficie aguas frías (de 22 a $23{ }^{\circ} \mathrm{C}$ ), y comienza el período de renovación de la masa de agua (Okuda 1981). La zona recibe los aportes de la surrgencia, las descargas urbanas y la camaronera, ocasionando aumentos en el nitrato y nitrito (con máximos en febrero), amonio y fosfato. Así mismo, aumenta la actividad fotosintética originando una buena oxigenación en las zonas central y occidental $\left(>4,8 \mathrm{ml}^{\mathrm{l}^{-1}}\right)$, no así para la oriental (estaciones 1, 2 y 3). Se observa además un incremento del fitoplancton, con dominio de los dinoflagelados en superficie y fondo, seguido de microflagelados y otros (Fig. 1). Tal comportamiento en zonas de surgencias ha sido atribuido a cambios en las condiciones hidrográficas (Eppley y Harrison 1975), y a ventajas competitivas en los estadios tempranos o tardíos de la surgencia debido a cambios químicos en la columna de agua (Blasco 1977). Por otra parte, Siaburth y Davis (1982) indicaron que una composición de fitoplancton dominada por esos grupos es típica de una fase posterior a una floración. El aumento de estos dos grupos se produjo al final del período de mayor abundancia y ocurrencia de floraciones de fitoplancton, lo que confirma lo señalado por estos autores.

Se observaron florecimientos de Thalassiosira rotula, Gonyaulax polygramma, Dinophysis acuminata, formas gimnodiniales y Heterocapsa sp. Esta última especie contribuyó significativamente a la abundancia del fitoplancton superficial. El crecimiento de estas especies no ocasionó mortandades de peces que son comunes en la zona de estudio. La concentración de clorofila bajó, alcanzando valores cercanos a $7 \mu \mathrm{g} . \mathrm{l}^{-1}$. El análisis a posterior (SNK al $95 \%$ ) para la clorofila, separó a las estaciones 2 y 6 por presentar la mayor biomasa y a la 11 y 13 las menores. Evidentemente existe una elevada producción fitoplanctóni- ca en la estación 2, causada por los aportes nitrogenados, particularmente amonio provenientes de la camaronera, además de una porción no estimada de algas que han constituido parte de la dieta de las larvas de camarones.

En mayo, a pesar de que los nutrientes aumentaron en todas sus formas, incluido el fosfato con un valor máximo de $2 \mu \mathrm{M} . \mathrm{I}^{-1}$, descendió la concentración de clorofila y la abundancia de grupos a nivel de fondo, a excepción de los microflagelados que incrementaron su número. Ferraz-Reyes y Fernández. 1990, encontraron para el Golfo de Cariaco valores altos de biomasa (entre 0.40 y $25 \mathrm{mg} \cdot \mathrm{m}^{-3}$ ), que contrastan con los valores encontrados en el presente estudio.

Estudios sobre fitoplancton en el Golfo de Cariaco (Ferraz-Reyes, 1976), indican una relación directa entre nutrientes y fitoplancton con valores mínimos de 283 org. $\mathrm{ml}^{-1}$ y máximos superiores a $6000 \mathrm{org}^{\mathrm{m} \mathrm{ml}^{-1}}$ para los años 70 y 71 . Estos difieren de nuestros resultados, ya que el fitoplancton creció mejor a bajas concentraciones de nitró eno $\left(<\mathrm{a} 4 \mu \mathrm{M}^{\mathrm{I}^{-1}}\right)$ correspondiéndose los máximos de fitoplancton con incrementos de fósforo y desfases con los de las bases nitrogenadas.

A pesar del aporte continuo de nutrientes en el área no se favoreció el crecimiento del fitoplancton, lo que pudiera ser atribuido al incremento del material en suspensión que limitan la penetración de la luz, incidiendo en la abundancia del fitoplancton.

\section{AGRADECIMIENTOS}

A los técnicos Oswaldo Gallardo, Simón Silva del Laboratorio de Toxicología del FONAIAP y al personal del Laboratorio de Oceanografía de la UDO por su participación en la colecta de muestras. A Ramón Guzmán e Isaac Sánchez Suárez, por la lectura crítica del manuscrito y procesamiento de datos estadísticos. Al Ejecutivo del estado Sucre por el financiamiento para esta investigación.

\section{RESUMEN}

El fitoplancton fue estudiado mensualmente desde junio 1995 a mayo 1996, en 16 estaciones que reciben di- 
ferentes descargas, en el sector oriental del Golfo de Cariaco. Sólo la clorofila, las abundancias de diatomeas, dinoflagelados y totales sufrieron un efecto diferencial con la profundidad. La salinidad y el oxígeno sufrieron diferenciación con la ubicación de las estaciones. Los máximos de fitoplancton de noviembre-diciembre, se relacionaron con bajos niveles de nutrientes nitrogenados y temperatura, elevados niveles de fosfato, clorofila y oxígeno disuelto. De junio a octubre predominaron temperaturas cálidas, bajas concentraciones de nutrientes, oxígeno y abundancia del fitoplancton. En general la abundancia del fitoplancton fue baja. Las diatomeas dominaron durante el período analizado, pero los microflagelados y dinoflagelados lo hicieron ocasionalmente. Los máximos de fitoplancton presentaron relación con los incrementos de fósforo y desfases con los máximos de nitrógeno. A pesar del elevado aporte de nutrientes, el crecimiento del fitoplancton fue limitado debido a la gran cantidad de partículas en suspensión, que reducen la penetración de luz.

\section{REFERENCIAS}

Blasco, D. 1977. Red tide in the upwelling region of Baja California. Limnol. Oceanogr. 22: 255 - 263.

Eppley, R. W. \& W. G. Harrison. 1975. Physiological ecology of Conycalax polyedra, a red water dinoflagellate of southern California, p. 11-22. In LoCicero. V. R. (e.d.). Proc. Inter. Conf. (Ist) on Toxic Dinof lagellate Bløoms. Mass. Sci. Tech. Found. Wakefield, Massachusetts.

Ferraz - Reyes, E. 1976. Ciclo anual del fitoplancton en zonas de bancos naturales y de cultivo del mejillón Perna perna (L) en el oriente de Venezuela. Bol. Inst. Oceanogr. Univ. Oriente. 15: 119-132.

Ferraz-Reyes, E. 1987. Productividad primaria del Golfo de Cariaco, Venezuela. Bol. Inst. Oceanogr. Univ. Oriente. 26: 97-110: 8 tigs, I tab.

Ferraz-Reyes, E. \& E. Fernández. 1990. Ciclo anual de las bacterias heterotrofas planctónicas y del fitoplancton en el Golfo de Cariaco, Venezuela. Bol. Inst. Oceanogr. Venezuela. Univ. Oriente. 29: 43-56, 10 figs., I tab.
Gade, H. G. 1961. On the hidrographic conditions in the Gulf of Cariaco during the months from May to November 1960. Bol. Inst. Oceanogr. Univ. Oriente. 1: 21-46

Goldman, J. C., J. J. McCarthy \& D. G. Peavey. 1979. Growth rate influence on the chemical composition of phytoplankton in oceanic waters. Nature. 279: 210-215

MacIsaac, J. 1978. Diel cycles of inorganic nitrogen uptake in a natural phytoplankton population dominated by Gonyaulax polyedra. Limnol. Oceanogr. 23: 1-9.

Mandelli, E. \& E. Ferraz-Reyes. 1982. Primary production and phytoplankton dynamics in a tropical inlet, Gulf of Cariaco, Venezuela. Inter. Revue. ges. Hydrobiol. 67: 85-95.

Okuda, T. 1981. Water exchange and the balance of phophate in the Gulf of Cariaco, Venezuela. Coast. Estuar. Sci. 1: 274-281.

Richards, F. 1960. Some chemical and hydrographic observations along the north coast of South America. I. Cabo Tres Puntas to Curazao, including the Cariaco Trench and the Gulf of Cariaco. Deep Sea Res. 3: 214-228.

Siaburth, J. M. \& P. G. Davis. 1982. The role of heterotrophic nannoplankton in the grazing and nurturing of planktonic bacteria in the Sargasso and Caribbean Seas. Ann. Inst. Oceanogr. (Paris). 58: 285-295.

Simpson J. G. \& R. C. Griffiths. 1971. Afloramiento y producción biológica en el Golfo de Cariaco, Venezuela. Serie Recursos y Explotación Pesqueras. 2: 3-16

Strickland, J. \& T. Parson. 1872. A practical handbook of sea water analysis. Bull. Fish. Res. Board. Can. 167: $1-310\left(2^{\text {nd }}\right.$ edition $)$.

Utermöhl, H. 1958. Zur vervollkommnung der quantitativen phytoplankton-methodik. Mitt. Int. Verein. Theor: Angrew. Limnol. 9: 1-38. 